\title{
Numerical Study of the Mechanical Behavior of a Foundation Raft under the Hydrodynamic Influence of the Mechanical Characteristics of Clay Soils
}

\author{
Tsanga Menounga Hugues',2, Fokwa Didier1,3, Nde Martial'1, Ngwem Bahiya Blaise ${ }^{1,3}$ \\ ${ }^{1}$ Mechanics Laboratory, Doctoral Training Unit in Engineering Sciences, Doctoral School of Fundamental and Applied Sciences, \\ University of Douala, Douala, Cameroon \\ ${ }^{2}$ Department of Architecture and Urbanism, Institute of Fine Arts, University of Douala, Douala, Cameroon \\ ${ }^{3}$ Higher Normal School of Technical Education, University of Douala, Douala, Cameroon \\ Email: huguestsanga@gmail.com
}

How to cite this paper: Hugues, T.M., Didier, F., Martial, N. and Blaise, N.B. (2020) Numerical Study of the Mechanical Behavior of a Foundation Raft under the Hydrodynamic Influence of the Mechanical Characteristics of Clay Soils. Engineering, 12, 766-780.

https://doi.org/10.4236/eng.2020.1210054

Received: September 15, 2020

Accepted: October 25, 2020

Published: October 28, 2020

Copyright $\odot 2020$ by author(s) and Scientific Research Publishing Inc. This work is licensed under the Creative Commons Attribution International License (CC BY 4.0).

http://creativecommons.org/licenses/by/4.0/

(c) (i) Open Access

\begin{abstract}
The clay soils of the city of Douala are constantly saturated with water, which permanently favors the hydrodynamic behavior of the soils (swelling or consolidation). This phenomenon can cause serious disturbances in the structure of buildings resulting in the appearance of cracks in structures (buildings, road bridge, viaduct, etc.). The foundation raft is a very important structure in the dimensioning of structures. Given the soil-structure interactions, its mechanical characteristics must be the subject of a special study linked to the building environment. In this article, we present a study of the mechanical behavior of a foundation raft anchored in a laminate floor. The aim is to highlight the influence of the mechanical properties of the foundation soil on the evolution of the mechanical behavior of the raft. The method used is a numerical simulation. A physical model taking into account a 5-storey building based in Douala in the Denver district is studied. The foundation on the raft foundation of this building follows an elastic constitutive law with Mazars damage, and rests on a laminated soil of plastic elastic model with Camclay plasticity criterion. The ground-raft and ground-ground interfaces are carried out with the finite elements joined to three nodes (JOI3), and obey the Coulomb model; it is an expansion joint model with Mohr-Coulomb type criterion and associated flow. The numerical resolution is carried out by the finite element method, and the numerical simulations via the Cast $3 \mathrm{M}$ calculation code. The results from the simulations show that the mechanical characteristics of foundation soils, in this case the water content, the compactness, the state of consolidation, greatly influence the mechanical behavior of the foun-
\end{abstract}


dation slab. There is indeed a significant settlement and a great deformation of the raft foundation when the water content of the soil layers increases, and when the states of consolidation and compactness are low. This article allows us to predict and control the evolution of the behavior of the ground-structure interface of a raft foundation and to adopt a new model appropriate for the sizing of civil engineering structures.

\section{Keywords}

Raft Foundation, Water Content, Compactness, Consolidation, Settlement, Deformation, Numerical Simulation

\section{Introduction}

In Cameroon, the urbanization rate in 2010 was 52\%, for a total population estimated at 19,648,287 inhabitants, with 17 towns of at least 100,000 inhabitants. The cities of Douala (economic capital) and Yaoundé (political capital) which in 2005 alone housed $21.3 \%$ of the total population and $43.7 \%$ of the urban population, totaled in 2010 more than 5 million inhabitants (approximately 23.5\% of the total population of Cameroon) [1]. The consequence of this growth is the establishment of populations practically on all sites and on all types of soil, even those with poor mechanical and physical characteristics, previously considered to be non-building areas. These circumstances favor a high risk of significant damage (flooding, collapse and subsidence of houses) during variations in the physical characteristics of soils due to the different climatic seasons of the central and coastal regions.

Soils, like all other materials, deform when loaded. In accordance with the general principles of soil mechanics, the deformations of saturated clay soils are linked to variations in the effective stresses, that is to say, to variations in the difference between the total stresses and the pressure of the pore water. Total stresses are created by the forces of gravity and by other loads applied to the surface of the soil (by embankments, shallow foundations, slabs, etc.) or inside the soil mass (deep foundations, tunnels), etc. [2]. The foundations of the structures undergo deformation, due to the variation of the climate and the permanent hydrodynamics of the soils. It is important to control and predict the behavior of soil characteristics in order to avoid possible degradation that could occur in the foundations of structures. In this article, it is about making a comparative study of the experimental results (geotechnical studies in situ), and a numerical model using the finite element code which will allow us initially to verify the results of the experimental data, and then to predict in the long term the behavior of the soil according to the physical parameters [3].

\section{Methods}

The uncertainty on the mechanical properties of soils linked to the heterogeneity 
within the same layer, results in an uncertainty on the amplitude of settlements and their evolution over time. The calculations give an idea of the differential settlements that can be expected at a given time. They can lead to fairly long consolidation times, and it may be necessary to consider an acceleration of settlements either by pre-loading or by intensified drainage. In this study we considered the values from the soil report note then we carried out experimental verifications on the site in order to take soil samples for laboratory studies in order to verify the results of the geotechnical report (content of water, void index, particle size analysis). We then, using Terzaghi's method [4], evaluated the settlement that could occur in the long term. With this result we formulated a numerical model in the CAST3M software in order to compare the calculation prediction and the behavior of the soil characteristics.

\subsection{Experimental Data}

The model chosen in (Figure 1) is designed according to the project which must receive a raft under a laminate floor of 4 layers.

Following a geotechnical survey campaign which took place on the study site of the project, we have recorded in Table 1 the values of the various limit pressure and in Table 2 it is a summary of the physical characteristics of the soil in place.

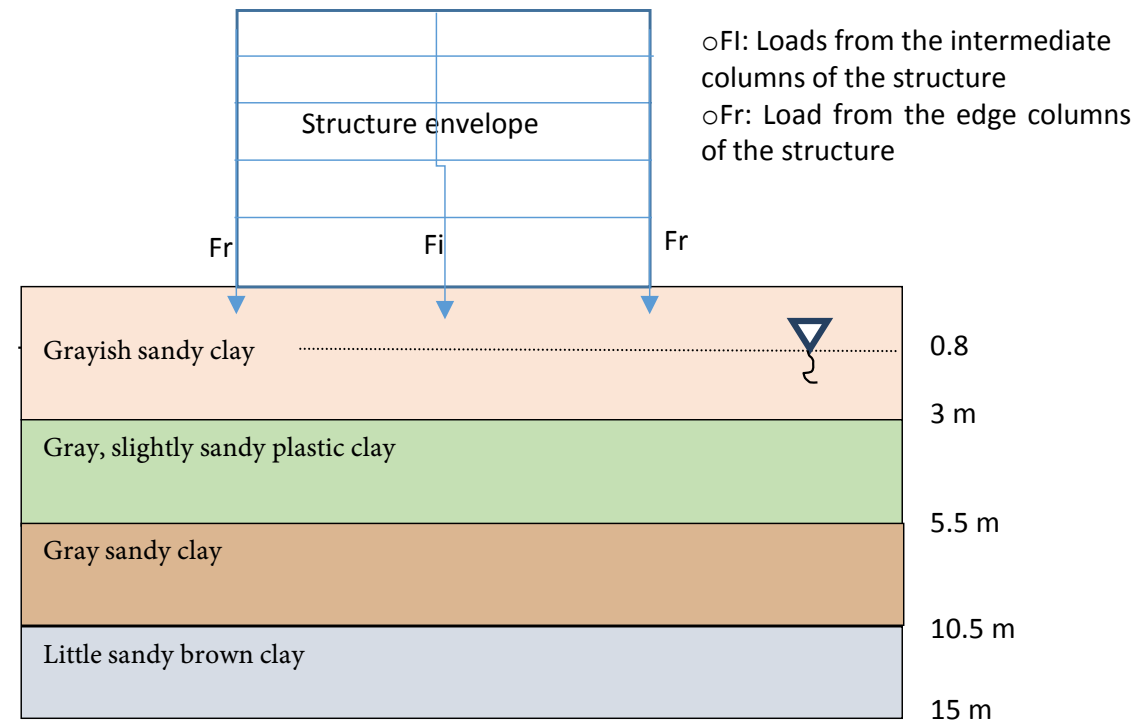

Figure 1. Model of the study soil structure in situ.

Table 1. Summary of the limit pressure analysis from the geotechnical report.

\begin{tabular}{|c|c|c|c|c|c|c|c|c|}
\hline Depth (m) & shapes & $\begin{array}{l}\text { Number } \\
\text { of values }\end{array}$ & $\begin{array}{c}\text { Thickness } \\
\text { (m) }\end{array}$ & Average & $\begin{array}{l}\text { standard } \\
\text { deviation }\end{array}$ & $\begin{array}{l}\text { Min } \\
(\mathrm{MPa})\end{array}$ & $\begin{array}{c}\operatorname{Max} \\
(\mathrm{MPa})\end{array}$ & Moy- $0.5 \sigma$ \\
\hline 0 to 3 & Grayish sandy clay & 3 & 3 & 0.97 & 0.55 & 0.44 & 1.55 & 0.70 \\
\hline 3 to 5.5 & Gray, slightly sandy plasticclay & 2 & 2 & 1.81 & 0.76 & 1.28 & 2.35 & 1.43 \\
\hline 5 to 10.50 & Gray sandy clay & 5 & 5.5 & 2.00 & 0.19 & 1.70 & 2.20 & 1.91 \\
\hline 10.50 to 15 & Little sandy brown clay & 5 & 4.5 & 1.95 & 0.07 & 1.86 & 2.03 & 1.92 \\
\hline
\end{tabular}


Table 2. Summary of geotechnical characteristics.

\begin{tabular}{ccccc}
\hline shapes & Roof/NL & Thickness $(\mathrm{m})$ & $\mathrm{Pl}^{*}(\mathrm{Mpa})$ & Em (Mpa) \\
\hline Grayish sandy clay & 0 & 3 & 0.70 & 5.18 \\
Gray, slightly sandy plastic clay & 3 & 2 & 1.43 & 20.41 \\
Gray sandy clay & 5.5 & 5.5 & 1.91 & 22.48 \\
Little sandy brown clay & 10.5 & 4.5 & 1.92 & 26.48 \\
\hline
\end{tabular}

\section{Verification of Lift and Settlement from in Situ Data}

The verification of the bearing capacities and the calculation of the footing's settlements are carried out using the values of the loads which will be exerted in the subsoil. In our case, we have the maximum load $\mathrm{Cm}=31 \mathrm{MN}$, calculated on the basis of the load drops. These are shallow foundations, namely a general raft of dimensions $15.40 \times 21 \mathrm{~m}$. The results of verification of settlements by the pressuremeter method are as follows: Calculation method of settlements according to Terzaghi.

The calculation of the overall settlement $\Delta h$ of a laminate floor by several compressible saturated layers is generally evaluated by:

$$
\Delta h=\Delta h i+\Delta h c+\Delta h s+\Delta h f
$$

- $\Delta h i$ : this is the immediate settlement, it depends on the overload $(\Delta \sigma)$, the compressible soil thickness $(h)$, a geometry factor of the medium $I$ and the deformation modulus $(E)$. This settlement occurs before any drainage has had time to take place. it is expressed by:

$$
\Delta h i=\frac{\Delta \sigma}{E} I
$$

- $\Delta h c$. This is a primary consolidation settlement of zero lateral strain, linked to the drainage of the multilayer system where there is an effective initial stress $\left(\sigma_{0}^{\prime}\right)$ uniformly overloaded by $\left(\Delta \sigma^{\prime}\right)$. This relation is given by:

$$
\Delta h c=H \frac{C_{c}}{1+e_{o}} \log \frac{\sigma_{0}^{\prime}+\Delta \sigma^{\prime}}{\sigma_{0}^{\prime}}
$$

- $\Delta h s$. This is the secondary settlement at zero lateral strain, corresponding to a creep of the skeleton after dissipation of the pore overpressure.

- $\Delta h f$. This is the settlement caused by the lateral movements of the soil.

Based on the calculations made, the final settlement is estimated at.

$$
\Delta h=\Delta h i+\Delta h c=0.0263 \mathrm{~cm}
$$

\subsection{Modeling and Numerical Simulation of the Mechanical Behavior of the Raft Foundation}

\subsubsection{Geometric Model and Mesh}

The chosen geometric model consists of a ribbed raft, anchored in a laminate floor made up of $\mathrm{o}, \mathrm{x}, \mathrm{y}$. The following main assumptions are made:

- The soils are homogeneous and isotropic. The dimensions considered are 15.4 min width. 
- The triangular finite elements with quadratic interpolation (tri6: triangle with 6 nodes and 2 degrees of freedom by node (Ux; Uy)) are used for the mesh of the base and the layers of soil. The resolution being partly carried out at the nodes of the mesh, this thus makes it possible to densify the nodes in the model and to approach the real solution as well as possible.

Figure 2 illustrates the reduced model of the problem formulated and Figure 3 the mesh of the geometry of the field of study of the problem.

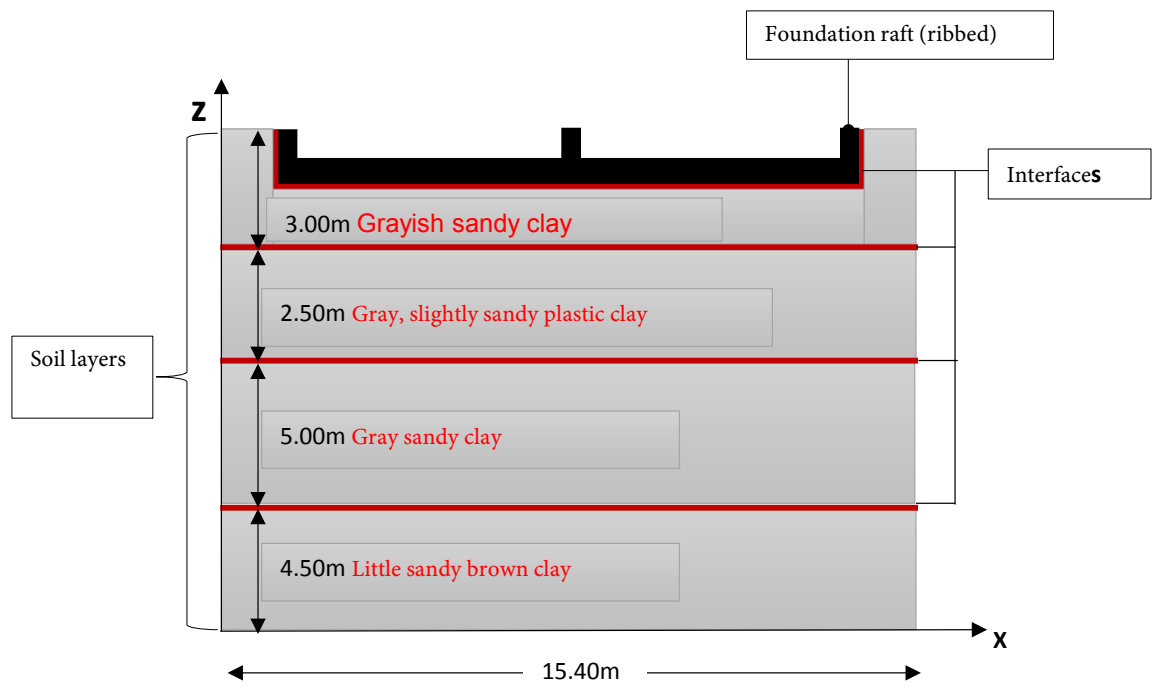

Figure 2. Geometric model of the problem.

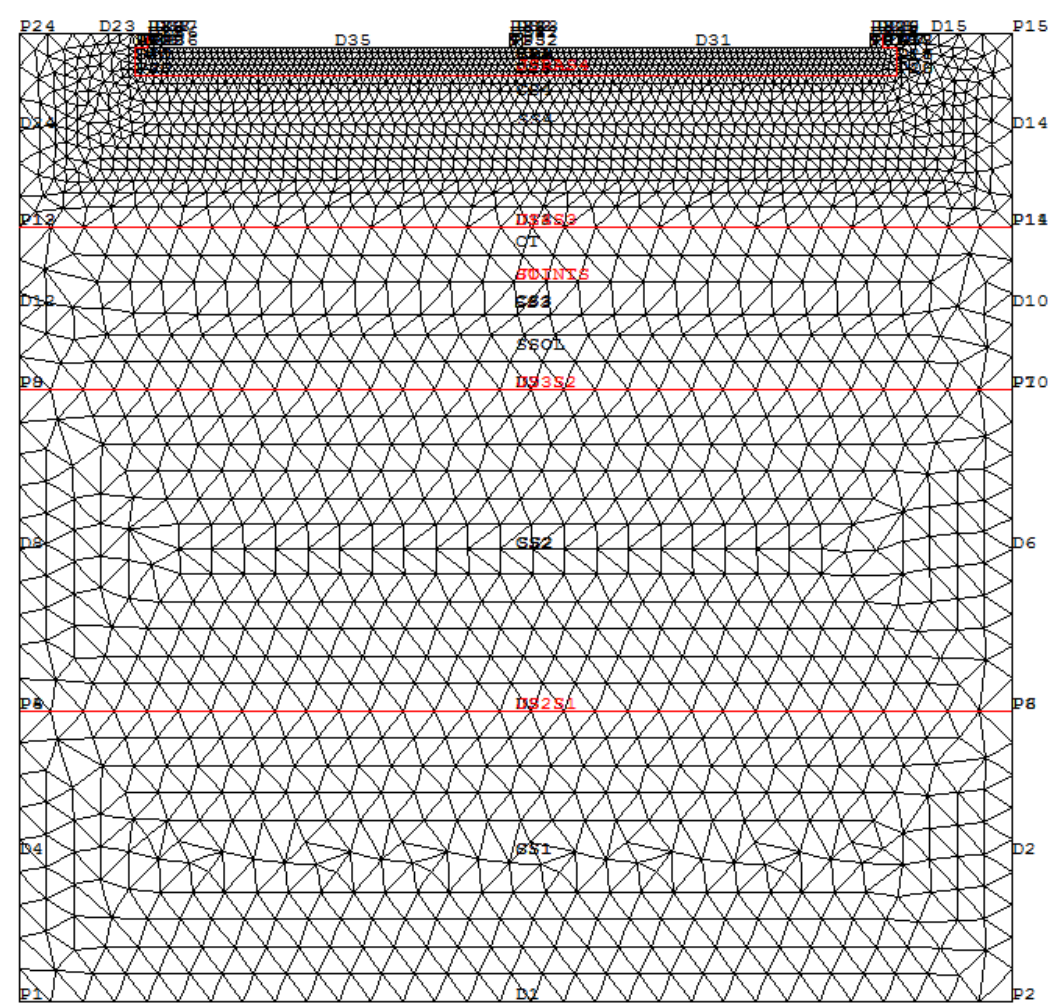

Figure 3. Mesh of the geometry of the study area. 


\subsubsection{Behavior Models}

\section{1) Mazars mechanical model for the raft foundation}

The foundation raft has a model of elastic mechanical behavior with Mazars damage. The damage variable " $D$ " constitutes an observable state variable for the material [5] [6]. The internal variables generally highlighted for this model are the following ones:

- Plastic or viscoplastic deformation:

$$
\varepsilon^{p}=\varepsilon+\varepsilon^{e}
$$

- The variable of scalar nature, characterizing isotropic hardening

$$
P=\int_{0}^{t}\left(\frac{2}{3} \dot{\varepsilon}^{p}(\tau): \dot{\varepsilon}^{p}(\tau)\right)^{1 / 2} \mathrm{~d} \tau
$$

- The tensor variable of order 2 characterizing the kinematic hardening a In the space of constraints, the flow surface is represented by the function $f$

$$
f=f(\sigma, p, X, \dot{p}, T)
$$

Kuhn and Tucker [7] [8], have shown that for plastic flow to occur, two conditions must be met:

- The point representative of the stress state $\sigma^{*}$ must belong to the flow surface [9]:

$$
f=f\left(\sigma^{*}, p, X, \dot{p}, T\right)
$$

- Throughout the flow, the point representative of the stress state must not be able to leave the surface:

$$
\mathrm{d} f\left(\sigma^{*}\right)=\frac{\mathrm{d} f}{\mathrm{~d} \sigma}: \mathrm{d} \sigma^{*}+\frac{\mathrm{d} f}{\mathrm{~d} p} \mathrm{~d} p+\frac{\mathrm{d} f}{\mathrm{~d} X}: \mathrm{d} X+\frac{\mathrm{d} f}{\mathrm{~d} \dot{p}} d \dot{p}+\frac{\mathrm{d} f}{\mathrm{~d} T} \mathrm{~d} T=0
$$

The charge/discharge criteria become:

- $f<0$ is equivalent to the elastic behavior

- $f=0$ and $\mathrm{d} f=0$ is equivalent to plastic flow

- $f=0$ and $\mathrm{d} f<0$ is equivalent to the elastic discharge

\section{2) Modified Camclay mechanical model for soil layers}

The soil has an elastoplastic model of behavior with modified Camclay plasticity criterion. This model is based on the concepts of limit state and critical state; he postulates the existence of a limit state and critical state curve to describe the elastoplastic behavior of normally consolidated isotropic soils, under homogeneous stresses [10] [11]. Roscoe and Burland [12] write the charge function $F$ of this model in the plane $(p, q)$ by Equation (9).

$$
F(\sigma)=q^{2}+M^{2}\left(P^{\prime 2}-P^{\prime} P_{c}^{\prime}\right)
$$

$P_{c}^{\prime}$ the pre-consolidation pressure given from Khemissa, by Equations (10)-(12)

$$
\begin{gathered}
q=\sqrt{\left(\left(\sigma_{1}-\sigma_{2}\right)^{2}+\left(\sigma_{1}-\sigma_{3}\right)^{2}+\left(\sigma_{2}-\sigma_{3}\right)^{2}\right) / 2} \\
P^{\prime}=\operatorname{trace}[\bar{\sigma}]
\end{gathered}
$$




$$
P_{c}^{\prime}=P_{c 0}^{\prime} \exp \left[\left(\left(1+e_{i}\right) /(\lambda-k)\right) \varepsilon_{v}^{p}\right]
$$

$e_{i}$ represents the initial void index of the soil. $P_{c 0}^{\prime}$ is the initial pre-consolidation pressure, $\lambda$ the slope of the loading curve for a normally consolidated state and $k$ the slope of the unloading-reloading curve for an over-consolidated state.

$\varepsilon_{v}^{P}$ is the plastic component of the strain. The slope of the critical state line $M$ in the plane $(p, q)$, or coefficient of friction is defined by Equation (13). $M$ is determined by the triaxial compression test and defined by Equation (6).

$$
M=6 \sin \varphi /(1-\sin \varphi)
$$

$\varphi$ is the internal friction angle of the soil. As described by Equation (14), $M$ is the slope of the line representing the critical shear behavior of the soil, where the strains continue to develop without a change in stress state

$$
q=M P^{\prime}
$$

The elastic law associated with the Camclay model is characterized by the Young modulus $E$ and the Poisson's ratio $v$ (assumed constant). These parameters are taken into account by the voluminal compressibility modulus $K$ and the shear modulus $G$, given by Equation (15) and Equation (16)

$$
\begin{gathered}
K=\left(\left(1+e_{i}\right) / k\right) P^{\prime} \\
G=[3(1-2 v) / 2(1+v)] K
\end{gathered}
$$

3) Plastic model of Mohr Coulomb for the ground-raft and ground-ground interfaces

The zero-thickness element approach was used to model the joints of the ground-raft and soil-ground interfaces. This element follows the elastoplastic constitutive law, with Mohr-Coulomb plasticity criterion [13] [14] and associated flow (Coulomb model implemented in CAST3M). The scalar function associated with this model is given by the load function $\mathrm{f}$ such that:

$$
f\left(\sigma_{n}, \tau\right)=|\tau|-\sigma_{n} \operatorname{tg} \phi-c
$$

with $\mathcal{c}, \phi$, respectively the cohesion and the friction angle at the interface. $\sigma_{n}$ and $\tau$ the normal and shear stresses. Table 2 gives the numerical values of the parameters retained for the model.

4) The values of parameters used to perform this simulation

The numerical simulations are carried out using the Castem software, by successively varying the pré-consolidation pressure, the soil compacity (through the void index), and the Young modulus (function of water content). The numerical input parameters used in Table 3 were taken from a geotechnical study carried out at Las-Planas site. Table 4 illustrates the soil-raft interface parameters used for the numerical simulations.

The values in Table 5 are parameters taken into account for concrete compared to the Mazars model are listed in the table below; these values come from (Di Paola, 2011). 
Table 3. Soils parameters used for numerical simulations (Gaudin et Serratrice, 1986).

\begin{tabular}{cccc}
\hline PARAMETRES & VALEUR & PARAMETRES & VALEUR \\
\hline Initial void index & $e_{i}=0.38$ & pre-consolidation pression & $P_{c}^{\prime}=2.5 \mathrm{Mpa}$ \\
Coefficient of friction & $M=1.18$ & Elastic slope & $k=0.007$ \\
Cohesion & $c=1 \mathrm{Mpa}$ & Plastic slope & $\lambda=0.04$ \\
Poisson's ratio & $v=0.3$ & Shear modulus & $G=150 \mathrm{Mpa}$ \\
Young modulus & $E=390 \mathrm{Mpa}$ & & \\
\hline
\end{tabular}

Table 4. Parameters of soil-raft interface used for numerical simulations.

\begin{tabular}{cccc}
\hline \multicolumn{1}{c}{ PARAMETRES } & VALEUR & PARAMETRES & VALEUR \\
\hline interface normal stiffness & $\mathrm{KN}=980 \mathrm{Mpa} / \mathrm{m}$ & Friction angle & $\phi=30^{\circ}$ \\
interface shear stiffness & $\mathrm{KS}=375 \mathrm{Mpa} / \mathrm{m}$ & Dilalancy angle & $\psi=30^{\circ}$ \\
Maximum tensile strength & FTRC $=980 \mathrm{Mpa} / \mathrm{m}$ & & \\
\hline
\end{tabular}

Table 5. Parameters of concrete used for numerical simulations.

\begin{tabular}{cccc}
\hline PARAMETRES & VALEUR & PARAMETRES & VALEUR \\
\hline Poisson's ratio & $v=0.25$ & Correction for shear & 1.06 \\
Young modulus & variable & Tensile strain threshold & KTR0 $=1 \mathrm{E}-4$ \\
Concrete in compression & $\mathrm{BCOM}=1900$ & Concrete in tension & BTRA $=17,000$ \\
Steel in compression & $\mathrm{ACOM}=1.4$ & Steel in tension & ATRA $=0.8$ \\
\hline
\end{tabular}

\subsection{Boundary Conditions of the Soil-Raft System}

The mechanical blockings are applied to the geometries of the soils and the raft as illustrated by Figure 4 . Thus, the boundary conditions relate to the horizontal displacements (Ux) which are blocked on the lateral edges of the soil layers (lines D2, D6, D10, D14 and lines D4, D8, D12, D24), as well as the vertical (Uy) and horizontal (Ux) displacements at the base of the soil mass (line D1).

\subsection{Mechanical Loading: Forces Applied to the Ribs}

The loading of the structure takes place on the ribs of the raft foundation, as shown in (Figure 5(a)); upward vertical forces are applied to the upper side of the raft ribs. These applied forces will have the effect of generating stresses, strains and displacements in the raft foundation, which will then be transmitted to the soil layers through the interfaces. The amplitude of these quantities depends on the mechanical characteristics of the soil layers under stress. The calculation being done step by step, the incrementation of the forces $\Delta \mathrm{F}$ is a function of the time increments, following a monotonic curve described by Equation (18) and shown in (Figure 5(b)).

$$
F_{i+1}=F_{i}+\Delta F
$$

where $F_{i}$ is the force applied to the time index $i$, and $\Delta F$ is the force increment at each time index. $F_{i+1}$ the force applied to the time index $i+1$. 


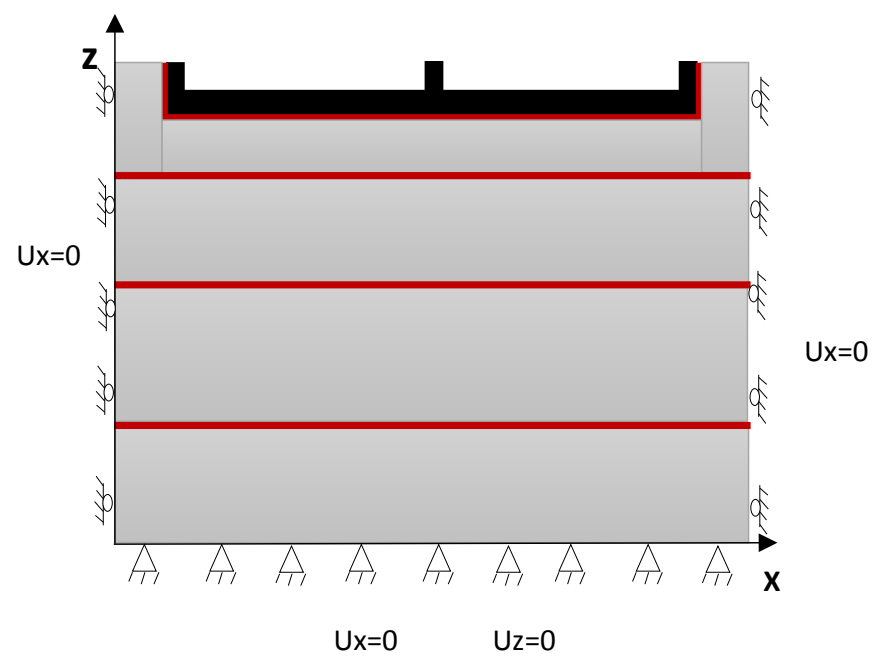

Figure 4. Mechanical blockages applied to the field of study.

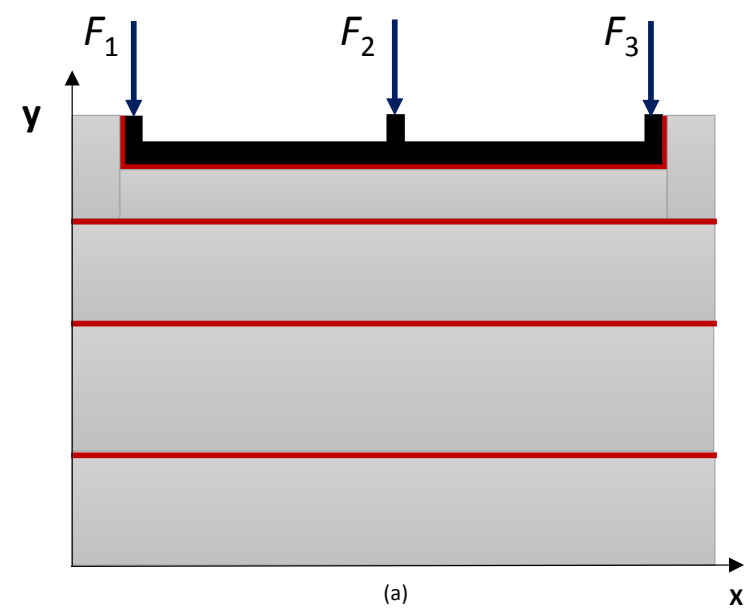

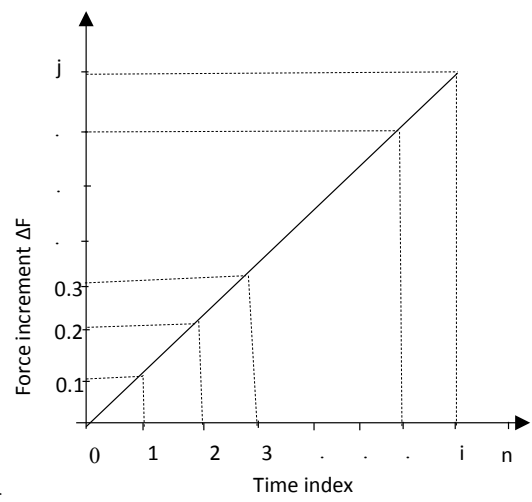

(b)

Figure 5. loading by forces applied to the ribs: (a) forces applied to the upper sides of the raft ribs, (b) monotonic curve of the force increment as a function of the time increment.

\subsection{Sequence of Numerical Computation}

A finite element calculation will be performed step by step using the Cast3m finite element code. The parametric study will be carried out by varying the mechanical parameters of the soil in turn (water content, compactness, consolidation). The results will be extracted with the nodes and elements of the mesh as illustrated by (Figure 6). This numerical computation will allow us to draw the curves of the total behavior of the raft foundation (global displacement of the raft foundation, global force-displacement), and the behavior curves local (stress-displacement) associated with the parametric study, and allowing to show the influence of the mechanical properties of the soil on the behavior of the raft.

\section{Analysis and Discussion of the Results}

To highlight the influence of the physico-mechanical characteristics of the soil on the behavior of the raft, Figures 7-14 show the local stress-displacement 


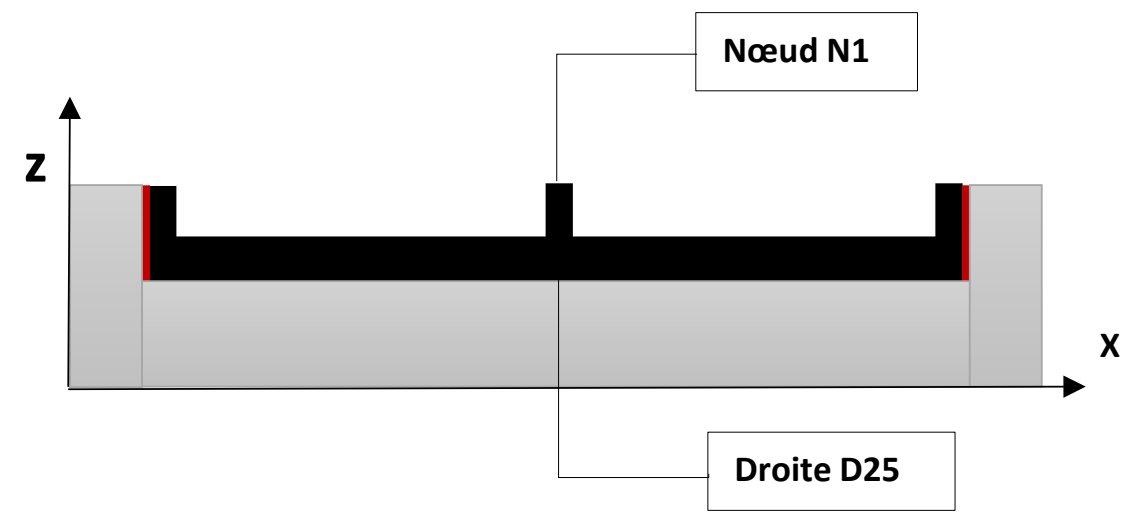

Figure 6. location of nodes and elements for the extraction of results and the plotting of curves.

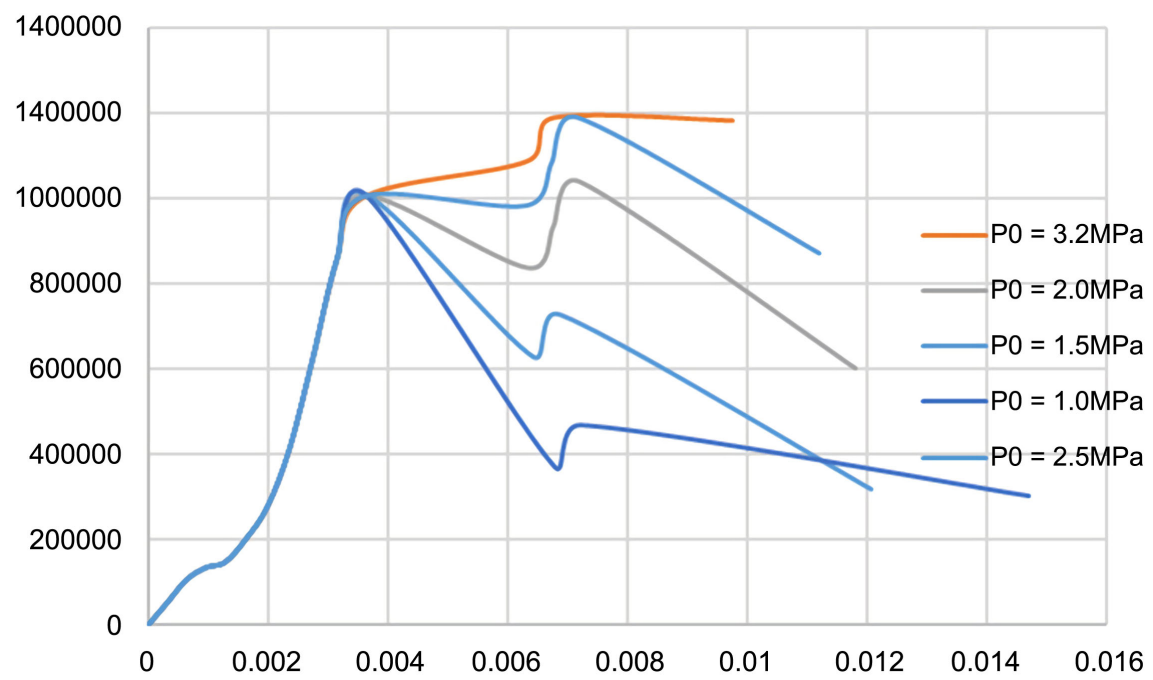

Figure 7. Evolution of the stress-displacement at the raft head as a function of the pre-consolidation pressure of the soil.
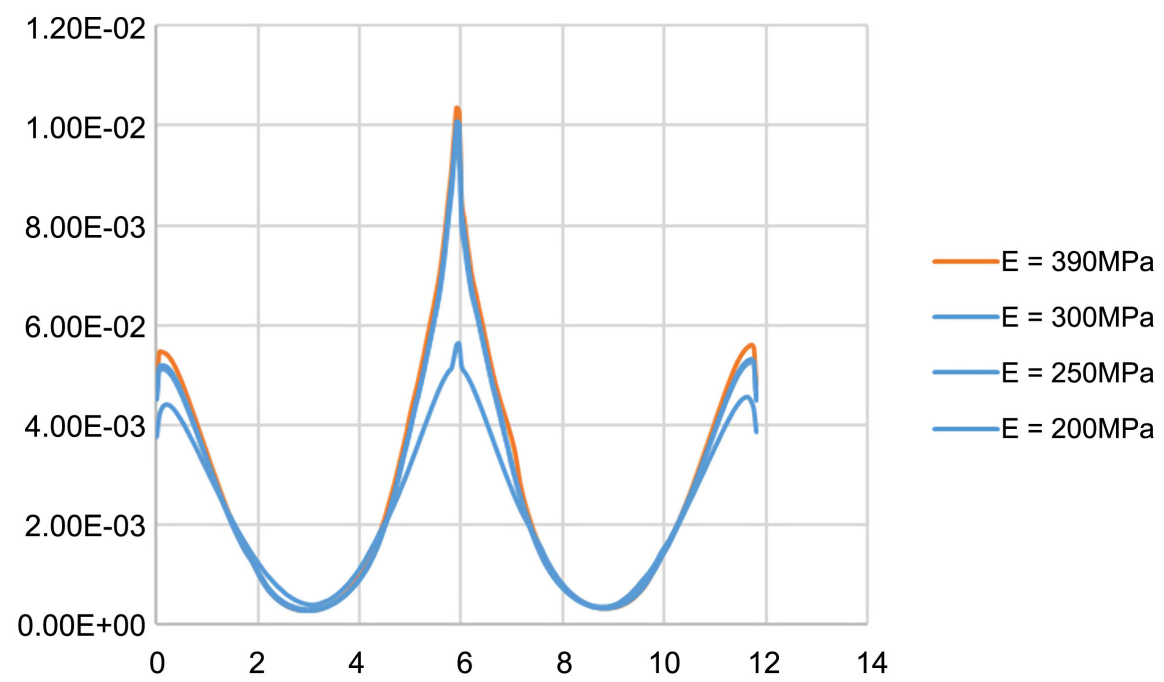

Figure 8. Force-displacement evolution of the raft as a function of the pre-consolidation pressure of the soil. 


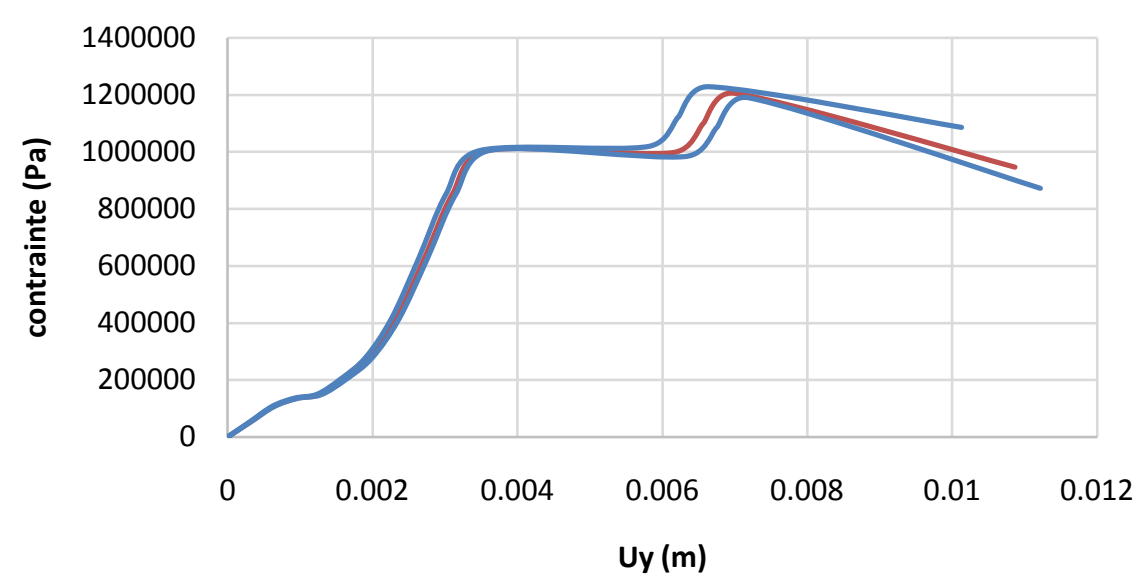

Figure 9. Stress-displacement evolution at the raft head as a function of the soil void index.

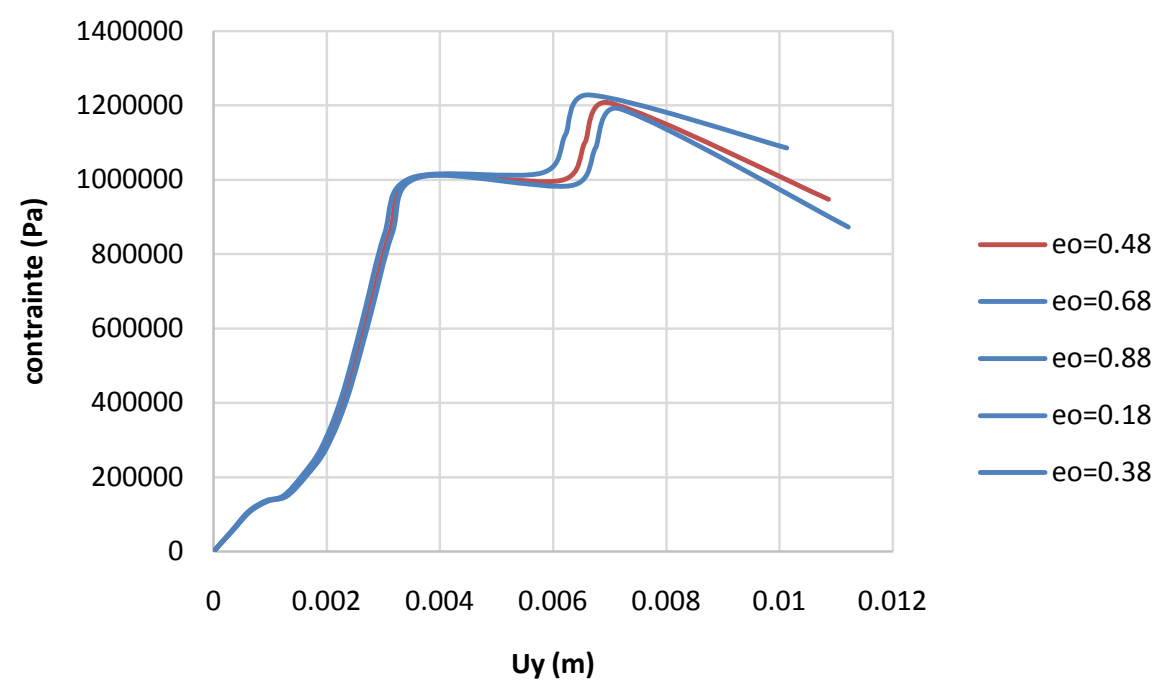

Figure 10. Evolution of the force-displacement of the raft as a function of the index of voids in the soil.

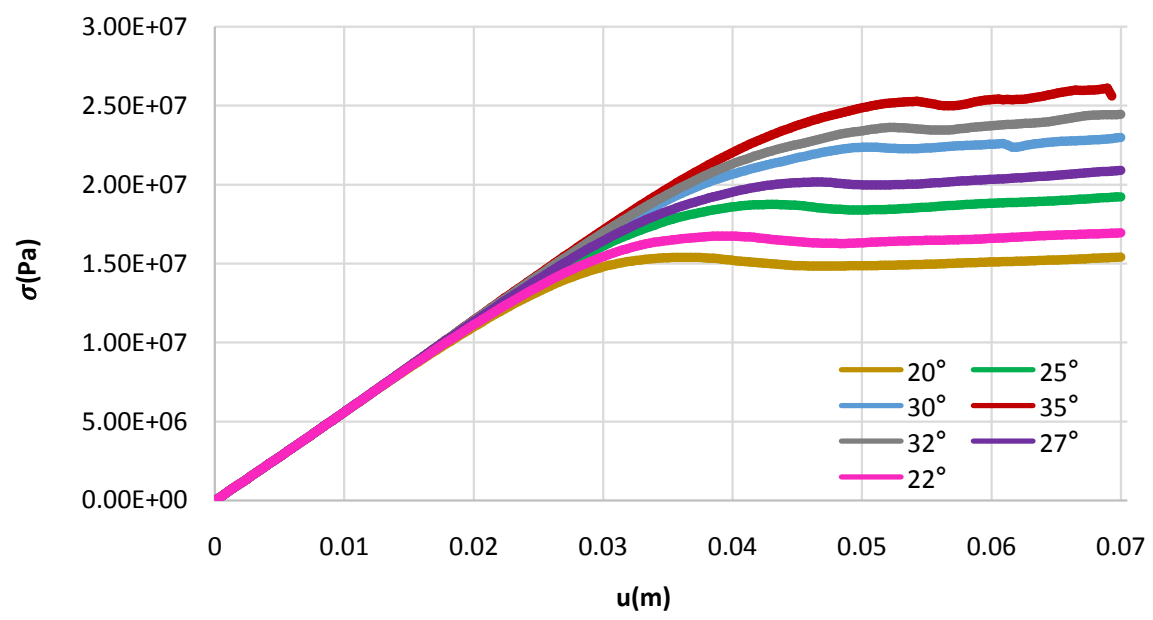

Figure 11. Stress-displacement at the pile head as a function of the internal friction angle of the soil. 


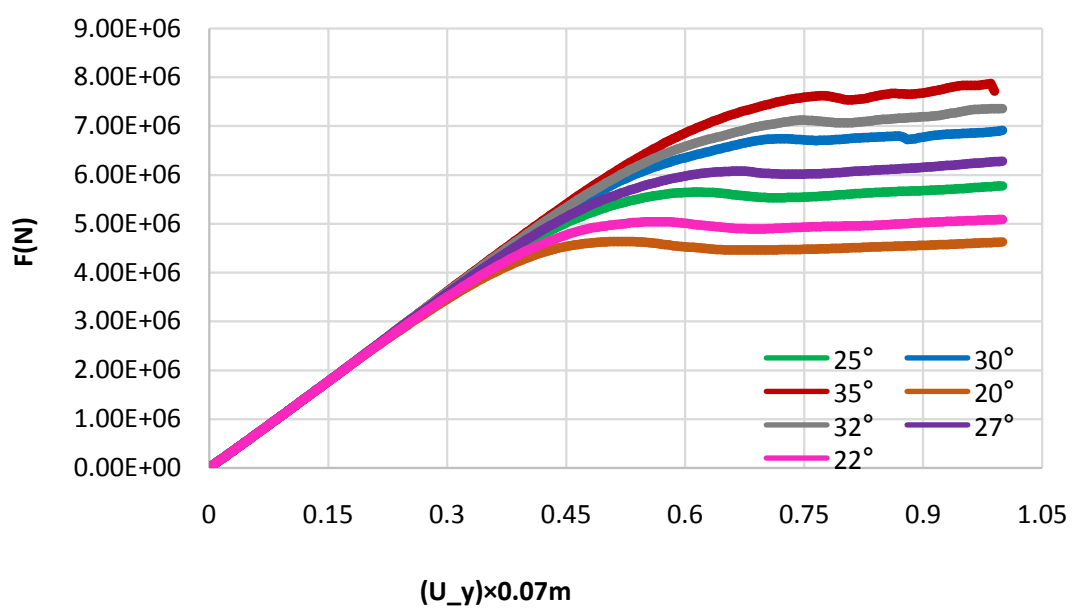

Figure 12. Force-displacement evolution of the pile as a function of the internal friction angle of the soil.

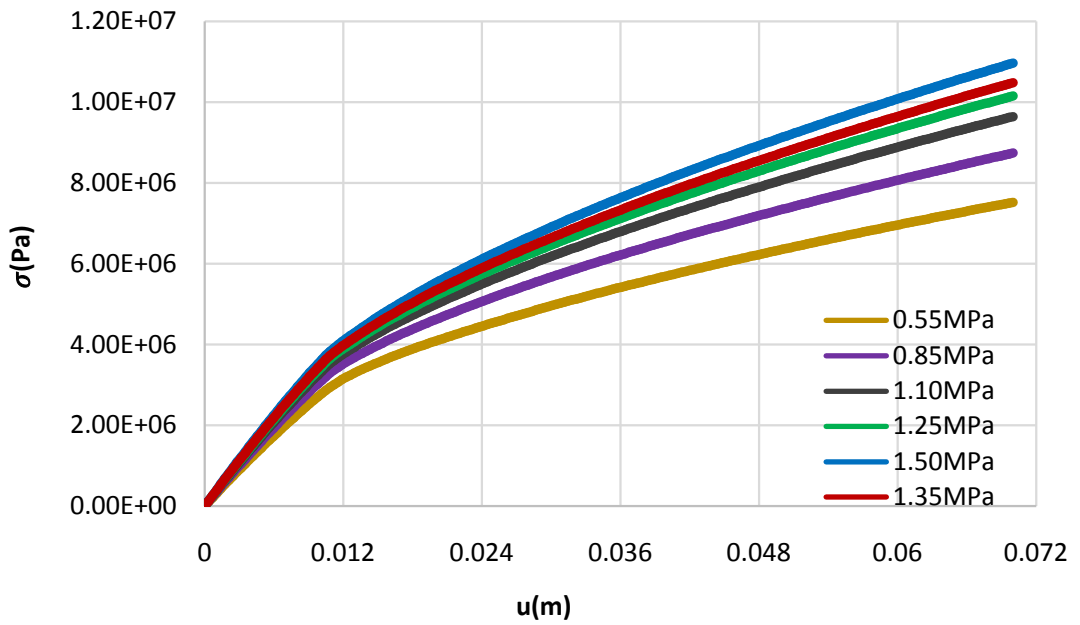

Figure 13. Evolution of the stress-displacement at the pile head depending on the cohesion of the soil.

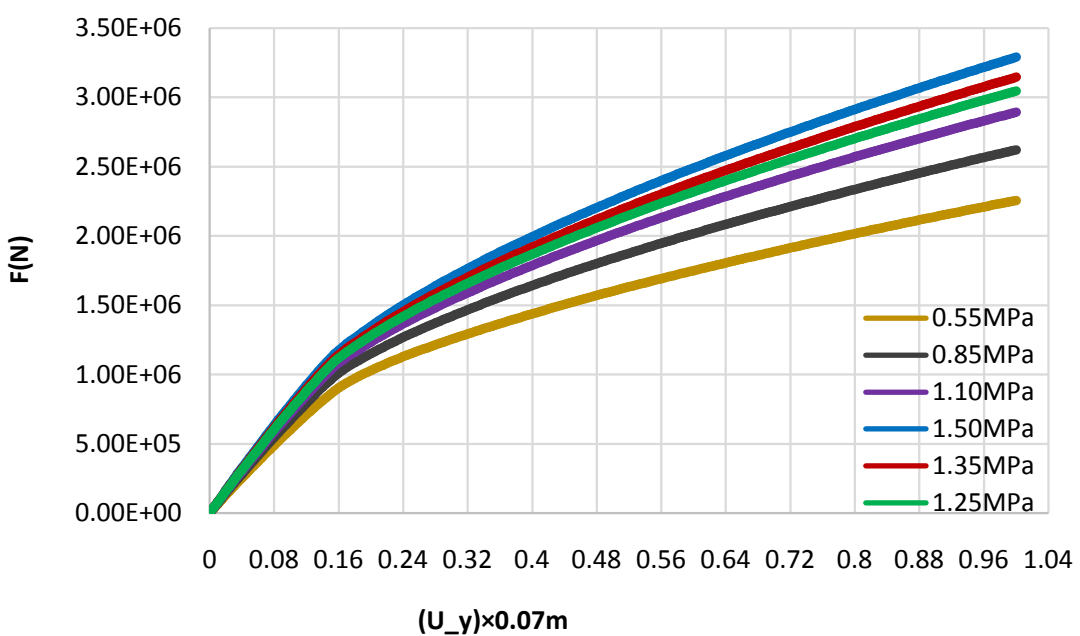

Figure 14. Evolution of the force-displacement of the pile according to the cohesion of the soil. 
curves at the head of the central rib of the raft, and the overall force-displacement of the raft, respectively. These curves are qualitatively in agreement with the work of Niandou [15].

\subsection{Influence of the Degree of Soil Consolidation}

The evolutions of the graph in (Figure 7) are qualitatively identical in appearance in the elastic zone (zone of small displacements), and all converge towards the same level characterizing the plastic flow at failure. However, stress peaks are observed which increase with the initial pre-consolidation stress, thus characterizing soils in a denser state. The stress and the breaking force mobilized therefore increase when the initial pre-consolidation pressure is greater. In fact, the dilatancy phenomenon which leads to the stress peak causes soil hardening [16], which is taken into account in the CamClay model by Equation (9), in which the initial pre-consolidation pressure occurs. Taking this parameter into account when designing the piles thus makes it possible to optimize the force mobilized at failure (Figure 8).

\subsection{Influence of the Initial Void Index}

Figure 9 and Figure 10 show qualitatively similar evolutions; however, there are nevertheless slight localized differences mainly in the area preceding the rupture. These changes show that the initial void index of the soil has a weak influence on the mechanical behavior of the pile before the soil breaks. Thus, when the void index decreases, the breaking stress is greater (Figure 9). This can be explained by the fact that a lower void index implies denser soil (high density index), capable of mobilizing a greater force at failure (Figure 10).

\subsection{Influence of the Cohesion and the Internal Friction Angle of the Soil}

The evolutions in graphs of Figure 11 and Figure 13, respectively 12 and 14 are qualitatively and quantitatively identical in the elastic zone (zone of small displacements), and all converge towards levels (plateau) characterizing the plastic flows at failure. However, these bearings exhibit greater ultimate stresses as the angle of internal friction and soil cohesion increase. The stress and the breaking force mobilized therefore increase with the cohesion (Figure 11) and (Figure 12) and the ground friction angle (Figure 13) and (Figure 14). Indeed, this last parameter is taken into account by the coefficient of friction (Equation (11)); the value of this coefficient increases with the angle of internal friction, and in the same order, increases the stress deflector leading to ground shear.

\section{Conclusion}

The objective of this article was to make a numerical simulation of the mechanical behavior of a foundation raft anchored in a laminate soil. The goal is to highlight the influence of the mechanical properties of the foundation soil in relation 
to the evolution of the mechanical behavior of the foundation raft subject to hydrodynamic variations of the physical parameters of the soil in the city of Douala in Cameroon. It emerges from after the boundary conditions and the models taken into account in the formulation of the studied problem that, when saturated clays are subjected to loadings at high load rates, deformations occur. We can therefore note that this evolution of settlement in the soil depends on several parameters which interact according to their solicitations. For this, we were able to highlight the influence of its parameters and note that, the stress and the breaking force mobilized in the study increase when the initial pre-consolidation pressure is greater and the void index decreases when the breaking stress is greater and finally the stress and the breaking force mobilized therefore increase with the cohesion and the friction angle of the soil. The interest of the work lies in taking into account the dimensioning parameters of the foundations of solid structures. In terms of perspectives, we envision the demonstration of a structural soil relationship of saturated clay soil types as well as a characterization of the physical parameters of soils as a function of heavy loads.

\section{Conflicts of Interest}

The authors declare no conflicts of interest regarding the publication of this paper.

\section{References}

[1] Cameroon-Rapport-National-Habitat-III (2020). http://www.minhdu.org.cm/

[2] Magnan, J.P. (2013) Deformability of Soils. Settlements. Consolidation Deformability of Soils. Settlements. Consolidation, Engineering Techniques.

[3] Breysse, D. (2001) The Challenges of Modeling Terrain and Structures to Best Describe the Soil-Structure Interaction. In: Proc. of A. Caquot Conference, ENPC Press, Paris, 1-2.

[4] Rousselot, D. (1975) Simulation of Soil Settlements according to the Theory of One-Dimensional Consolidation of Terzaghi. BRGM.

[5] Mazars, J. and Berthaud, Y. (1989) An Experimental Fracture Applied to Concrete to Create Diffuse Damage and to Highlight Its Unilateral Character. C.R. Académie des Sciences de Paris, 308, 579-584.

[6] Mazars, J. (1984) Application of the Damage Mechanics to the Nonlinear Behavior and to the Failure of Structural Concrete. Doctoral Thesis, University of Paris, Paris, 6.

[7] Kuhn, H. and Tucker, A. (1951) Nonlinear Programming. In: Proceedings of the second Berkeley Symposium on Mathematical Statistics and Probability, University of California Press, Berkeley, 481-492.

[8] Bouzitat, J. (1969) The Conditions of Kuhn and Tucker in Mathematical Programming. Notebooks of the University Operations Research Office. Research Series, Volume 12, 37-134.

[9] Farah, E. (2009) Constitutive Model of the Viscoplastic Behavior of a CFC Material. Master of Applied Sciences Department of Mechanical Engineering Montreal Poly- 
technique School.

[10] Khemissa, M. (2004) Comparison of Two Models for the Analysis of Tunnel Convergence Bridge and Pavement Laboratories Bulletin.

[11] Azizi, F. and Josseaume, H. (1988) Law of Behavior of Steep Soils Determination of the Limit State Curve of Romainville Green Clay Series: Geotechnique-Mecanique Des sos-sciences de la terre GT-33.

[12] Roscoe, K.H. and Burland, J.B. (1968) On the Generalized Stress-Strain Behavior of Wet Clay. In: Heyman, J. and Leckie, F., Eds., Engineering Plasticity, Cambridge University Press, Cambridge, 535-609.

[13] Pankaj, B.N. (1997) Detection of Multiple Active Yield Conditions for Mohr-Coulomb Elasto-Plasticity. Computers and Structures, 62, 51-61. https://doi.org/10.1016/S0045-7949(96)00267-2

[14] Sloan, S.W. and Booker, J.R. (1986) Removal of Singularities in Tresca and Mohr-Coulomb Yield Functions. Communications in Applied Numerical Methods, 2, 173-179. https://doi.org/10.1002/cnm.1630020208

[15] Niandou, H. (2015) Soil-Structure Interaction: Deformation of a Raft Foundation on a Heterogeneous Soil in 3D. 33rd AUGC Meetings, ISABTP/UPPA, Anglet, 162-171.

[16] Bahda, F. (1997) Study of the Behavior of Sand in the Triaxial Apparatus: Experiment and Modeling. Mechanics physics.med-ph Ecole Nationale des Ponts et Chaussées, tel-00523153f. 